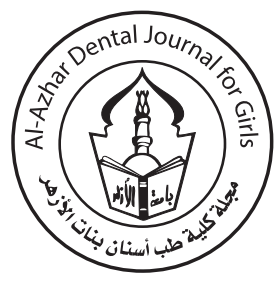

\title{
Effect of Using Two Treatment Modalities on the Alveolar Bone Height in Flat Ridge Cases
}

\author{
Safaa M. Ragab ${ }^{1 *}$, Amany A. Abdel Fattah' ${ }^{2}$, Nahed M. Adly ${ }^{3}$
}

Codex : 05/21.04

azhardentj@azhar.edu.eg

http://adjg.journals.ekb.eg

DOI: $10.21608 /$ adjg.2021.23165.1226

Restorative Dentistry

(Removable Prosthodontics, Fixed

Prosthodontics, Endodontics, Dental Biomaterials, Operative Dentistry)

\section{KEYWORDS}

Single Implant,

Bone Resorption,

Flexible Denture

\begin{abstract}
Purpose: to evaluate the effect of using two treatment modalities on the alveolar bone height in flat ridge cases. Materials and methods: Ten completely edentulous male patients were selected. Age of the patients ranged from 55-65 years old. All patients had resorbed lower ridges. The patients were divided into two groups, five patients each. All group (A) Patients received conventional flexible denture while, all group (B) patients received overdenture supported by single sympheseal implant. Mandibular bone height was measured by Cone Beam Computerized Tomography (CBCT) for both groups using stent containing radio-opaque stainless steel wires at posterior region corresponding to $(5,6,7)$ denture teeth at the time of flexible denture/overdenture delivery and 6,9, 12 month after. Results: Regarding intergroup comparison of the change in bone height (\%) group (A) had a higher mean value of bone height changes than group (B) which was found statistically not significant. Regarding frequency and percentage values for patient satisfaction questionnaire answers there were no significant differences in the answers of both groups. Conclusion: Within the limitation of this study, it could be concluded that, there was no significant difference between flexible complete denture group and single implant flexible overdenture group regarding posterior mandibular bone resorption and patient satisfaction.
\end{abstract}

\section{INTRODUCTION}

Residual Ridge Resorption was assessed as major oral disease item that characterized by loss of jaw bone after teeth extraction. The edentulous alveolar ridge resorption is continuous procedure that occurs during life, thus decline of the alveolar ridge height occur

- Paper extracted from Doctor thesis" Effect of Using Two Treatment Modalities on the Alveolar Bone Height in Flat Ridge Cases"

1. Dentist at the Ministry of Health, Egypt

2. Professor of Removable Prosthdontic faculty of Dental medicine for girls Al-Azhar University, Cairo, Egypt

3. Lecturer of Oral and Maxillofacial Surgery Faculty of Dental Medicine for girls Al-Azhar University, Cairo, Egypt

* Corresponding author email: safaaragab77@yahoo.com 
in all patients. The contour, size and tolerance of residual ridges afford the foundation of stability, retention, and support of complete denture ${ }^{(1,2)}$. Variances were detected between individuals in the extent and rapidity at which alveolar bone is lost, which were ascribed to many factors such as age, sex, anatomy of the face, oral hygiene, parafunction habits, time elapsed since patients have been edentulous, systemic disorders, status of nutrition, general health, osteoporosis, metabolic rate, and medications. It was supposed that mandibular bone loss is four times greater than that of maxillary loss, dissimilarities in resorption were returned to the fact that the complete lower denture supporting surface is reduced, smaller and its basal seat shape is less advantageous shape thus, the lower ridge is expected to endure higher forces during function transmitted through the denture than maxillary ridge thus, the pressure applied on it is much greater ${ }^{(1-4)}$. Diminishing the height of the edentulous ridge leads to improper mandibular denture function, in cases of severe mandibular alveolar ridge resorption discomfort and instability of the conventional acrylic resin denture is encountered by patient hence, his social distress ${ }^{(2-5)}$.

Over years complete tissue-supported removable prostheses were considered as the first choice for edentulous patients treatment. Regardless of all the argument for appropriate age, oral state, general health, social and economic status of the patient, a carefully fabricated complete removable denture is a safe, predictable and economical treatment to rehabilitate edentulous patient especially in developing countries ${ }^{(5)}$. during denture construction attention should be paid toward understanding of the biologic aspect and its relation to the denture base and supporting tissues, coverage of broad area within the physiological limits under denture base distribute forces and allow for denture stability and support, hence reduce amount of stresses transferred to the ridge preserving the alveolar ridge ${ }^{(6-8)}$.

Flexible dentures are considered perfect alternatives to conventional acrylic dentures.
These dentures are easy to wear and satisfying for patients because they are considerably thinner, more retentive and stay confidently in place when compared to conventional acrylic dentures. Also do not cause any allergic responses and resistant to breakage ${ }^{(9,10)}$. Implant-supported prosthesis is considered as a dependable practice in rehabilitation of complete edentulism, that accepted world-wide, due to its efficacy regarding function, nutrition, and entire quality of life, one of its advantage is preserving jaw bone. Dental implants integrate with the jawbone reducing the rate of bone loss attributed to conventional dentures. An early issued implant can even decelerate the unavoidable residual ridge resorption ${ }^{(5-7)}$.

Single implant supported prosthesis has been proposed as a conservative and less costly treatment choice. The simplicity of this technique and its lower expenses indorses this line of treatment as an unconventional treatment option for mandibular edentulism $^{(11,12)}$.

This study was conducted to evaluate the effect of using two treatment modalities on the alveolar bone height in flat ridge cases.

\section{MATERIAL AND METHODS}

Ten completely edentulous male patients with resorbed lower ridges without any undercut exostosis or tori were selected to share in this study. Patients age ranged from 55-65 years old. Patients had healthy mucosa free from any ulceration, inflammation or infections. At least 2 years were elapsed after last extraction. All patients were free from neuromuscular and tempromandibalar joint disorders. Patient was free from any systemic disease that might interfere with dental implant placement and/ or osseointegration or enhances the rate of residual ridge resorption. Clinical procedure and the steps of the work were explained for all patients and patients' acceptance consent has been obtained with the Research Ethics Committee (REC) approval. Female patients were excluded. Patient history and 
clinical examination for dental, medical, intra and extra oral, radiographic examination using preoperative digital orthopantogram and lab investigation have been done for all patients. Conventional flexible maxillary and mandibular complete denture were constructed for all patients. Patients were divided into two groups, five patients each. Group (A) received conventional flexible denture while Group (B) received flexible overdenture supported by single implant in sympheseal area with ball and socket attachment (Fig.1).

Radiographic template was made with metallic ball in the middle, for all patients in group (B). Patients were subjected to $\mathrm{CBCT}$ radiograph with the stent in place showing the position of the ball to allow measurement of implant dimension from examined CBCT axial, coronal and sagittal cuts using software viewer program. Surgical Procedures were carried out using Flapless surgical technique, standardization of implant length and width in all cases has been regarded (length $13 \mathrm{~mm} \&$ width $3.2 \mathrm{~mm}$ ).

After three months, osseointegration was confirmed by clinical and radiographic parameter after three months of implant placement, the cover screw was removed from the implant body the ball attachment was inserted. Denture was reliefed from the tissue side opposing to the ball attachment, all undercuts below the attachment was blocked by soft block-out wax to prevent the self-cure acrylic resin lock in the undercut. For denture pick up autopolymerization acrylic resin was placed into the created space in the lower denture fitting surface . The denture placed in the patient mouth then patient was instructed to close in centric occlusion. After resin had been set, denture was removed from patient's mouth and inspected for any voids around the sockets.The excess material was removed and the denture was finished and polished and delivered to the patient.

For both groups duplication of lower denture was made to be used as stent for radiographic evaluation of the bone height during intervals of the follow up period. Radio-opaque material (stainless steel wire) processed in the fitting surface of the lower duplicated dentures to represent posterior marker areas of 5, 6 and 7 acrylic teeth during evaluation of the bone height for both groups. Evaluation of bone height in the posterior edentulous area was done by CBCT at time of denture delivery and six, nine, twelve months after for group (A) the same for group (B) after implant loading. Measurements have been taken from right and left side of the mandible from the crest of the ridge up to the inferior border of the mandible as line was drawn tangential to the lower border of the mandible (Fig.2).

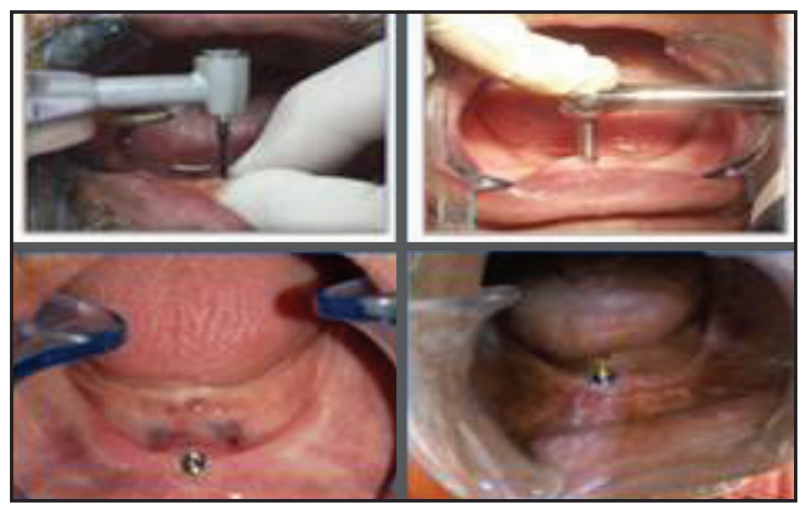

Figure (1): Sequence of implant placement

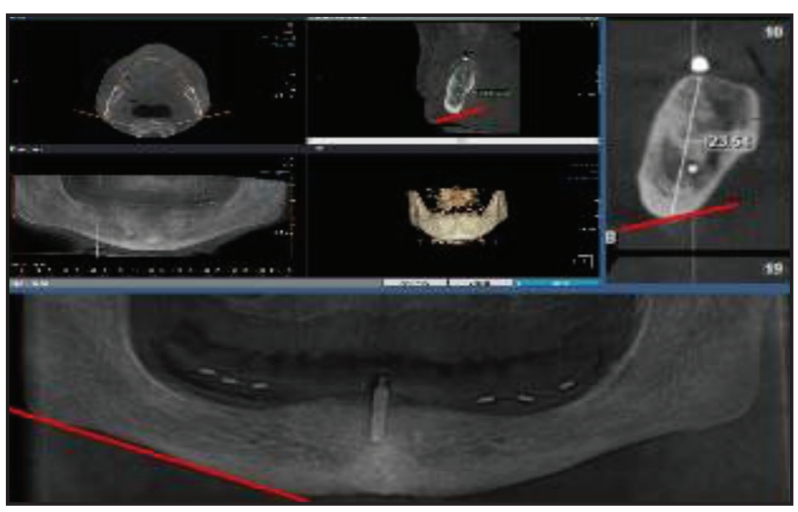

Figure (2): Reformated CBCT for measuring bone height 


\section{Statistical Analysis}

All the measurements from both group were collected and tabulated to be statically analyzed. Statistical analysis was performed with IBM $₫$ SPSS $₫$ (SPS Statistics Version 25 for Windows). Numerical data were presented as mean and standard deviation (SD). Data were explored for normality by checking the data distribution, calculating the mean and median values and using Kolmogorov-Smirnov and Shapiro-Wilk tests. Parametric data were analyzed using independent t-test for intergroup comparisons and one-way repeated measures ANOVA The significance level was set at $\mathrm{P} \leq 0.05$ for all tests

\section{RESULTS}

I- Changes of bone height within the two studied group at different follow up intervals intragroup comparison:

Table (1): Mean and Standard deviation (SD) values for bone height $(\mathrm{mm})$ in different follow-up intervals

\begin{tabular}{|c|c|c|}
\hline \multirow{2}{*}{ Follow-up } & \multicolumn{2}{|c|}{ Bone height (mm) (Mean \pm SD) } \\
\cline { 2 - 3 } & Group (A) & Group (B) \\
\hline Baseline & $23.65 \pm 4.52^{\mathrm{A}}$ & $18.89 \pm 1.57^{\mathrm{A}}$ \\
\hline 6 months & $23.26 \pm 4.55^{\mathrm{B}}$ & $18.65 \pm 1.60^{\mathrm{B}}$ \\
\hline 9 months & $22.90 \pm 4.56^{\mathrm{BC}}$ & $18.47 \pm 1.59^{\mathrm{C}}$ \\
\hline 12 months & $22.63 \pm 4.61^{\mathrm{C}}$ & $18.31 \pm 1.66^{\mathrm{C}}$ \\
\hline p-value & $<0.001^{*}$ & $<0.001^{*}$ \\
\hline
\end{tabular}

Different superscript letters indicate a statistically significant difference within the same vertical column *; significant $(p \leq 0.05) n s ;$ non-significant $(p>0.05)$

\section{$\operatorname{Group}(A)$ :}

There was a continuous decrease of bone height values starting from baseline $(23.65 \pm 4.52)$ until 12 months $(22.63 \pm 4.61)$ and there was a significant difference between values recorded at different follow-up intervals $(\mathrm{p}<0.001)$.

\section{$\operatorname{Group}(B)$ :}

There was a continuous decrease of bone height values starting from baseline $(18.89 \pm 1.57)$ until 12 months $(18.31 \pm 1.66)$ and there was a significant difference between values recorded at different follow-up intervals $(\mathrm{p}<0.001)$.

Intergroup comparison of $(\%)$ change of bone height between the two studied group:

Mean and Standard deviation (SD) values for bone height percentage change (\%) in both groups were presented in table (2)and (fig.3) .

Table (2): Mean and Standard deviation (SD) values of bone height percentage change (\%)

\begin{tabular}{|c|c|c|c|c|}
\hline \multirow{2}{*}{ Side } & \multirow{2}{*}{ Follow-up } & \multicolumn{2}{|c|}{$\begin{array}{c}\text { Bone height decrease } \\
\quad(\text { Mean } \pm \text { SD })\end{array}$} & \multirow{2}{*}{ p-value } \\
\hline & & Group (A) & Group (B) & \\
\hline \multirow{4}{*}{ 苛 } & Baseline- 6 months & $1.24 \pm 0.55$ & $1.28 \pm 0.53$ & $0.915 \mathrm{~ns}$ \\
\hline & 6-9 months & $1.80 \pm 2.79$ & $0.63 \pm 0.46$ & $0.381 \mathrm{~ns}$ \\
\hline & 9-12 months & $1.18 \pm 2.84$ & $0.87 \pm 0.43$ & $0.817 \mathrm{~ns}$ \\
\hline & Overall & $4.21 \pm 1.96$ & $2.75 \pm 1.24$ & $0.197 \mathrm{~ns}$ \\
\hline \multirow{4}{*}{ 馬 } & Baseline-6 months & $2.11 \pm 0.95$ & $1.34 \pm 0.43$ & $0.139 \mathrm{~ns}$ \\
\hline & 6-9 months & $1.40 \pm 0.42$ & $1.30 \pm 0.84$ & $0.831 \mathrm{~ns}$ \\
\hline & 9-12 months & $1.31 \pm 0.49$ & $1.01 \pm 0.75$ & $0.475 \mathrm{~ns}$ \\
\hline & Overall & $4.74 \pm 1.60$ & $3.61 \pm 0.95$ & $0.215 \mathrm{~ns}$ \\
\hline
\end{tabular}

From the above table and by comparing mean and SD values for bone height percentage changes in the right $\&$ left side of the mandible during the follow up periods $(0,6,9,12$ month) for both group it was shown that

\section{Right side:}

Group (A) (4.21 \pm 1.96$)$ had a higher mean value of bone height percentage change than group (B) $(2.75 \pm 1.24)$ yet the difference was not significant $(\mathrm{P}=0.197)$. 


\section{Left side:}

Group (A) (4.74 \pm 1.60$)$ had a higher mean value of bone height percentage change than group (B) $(3.61 \pm 0.95)$ yet the difference was not significant $(\mathrm{P}=0.215)$.

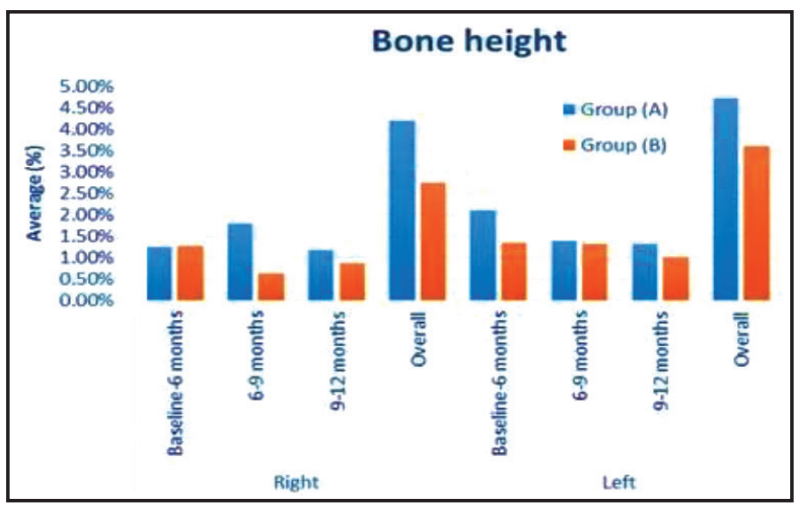

Figure (3): Bar chart showing average bone height percentage change $(\%)$

\section{II-Patient satisfaction}

Frequency and percentage values for answers to the patient satisfaction questionnaire chart were presented in (Fig.4)

There was no significant difference in the answers to the patient satisfaction questionnaire of both groups to different questions, There was no significant difference in the answers of both groups $(p=0.292)$. Majority of group (A) $4(80 \%)$ and all the cases in group (B) were very satisfied while only $1(20 \%)$ case of group (A) was satisfied.

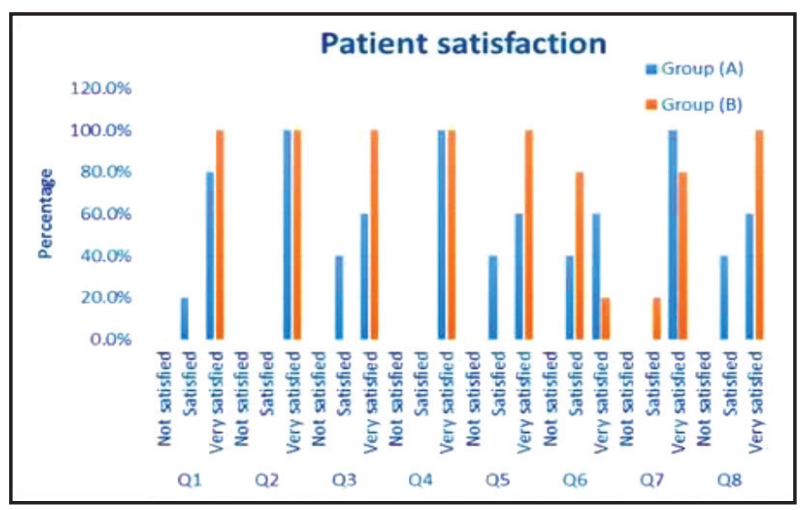

Figure (4): Bar chart showing percentage of answers to the patient satisfaction questionnaire

\section{DISCUSSION}

The current study showed that patients in Group (A) had a higher mean value of bone height decrease than those in group (B) during different intervals of follow up period regarding both right and left sides of the mandible however these differences found to be statically not significant $(p \leq 0.05)$. These findings came in accordance with previous study, that found slight significant difference in the residual ridge resorption between complete denture wearers and overdenture wearers ${ }^{(13)}$. However this came contrast with another study that reported that, dental implants integrate with the jawbone and intensely reduce the rate of bone loss ascribed to conventional dentures ${ }^{(14)}$. In previous study it was found that patients treated with implant overdenture presented at least twice the residual ridge resorption as patients treated with conventional complete denture ${ }^{(15)}$.

In this study the amount of bone resorption met with the findings of many previous long term studies that documented average of $1.5 \mathrm{~mm}-2 \mathrm{~mm}$ bone loss during the first year after functional loading of with annual rate of marginal bone loss about $0.2 \mathrm{~mm}^{(16-18)}$.

Comparing the percentage change of bone height (\%) during diffrenet follow up periods and regarding right and left side of the mandible respectively, over all comparison results showed that Group (A) $(4.21 \pm 1.96)$ had a higher mean value of bone height percentage change than group (B) $(2.75 \pm 1.24)$ however these differences were statistically not significant $(\mathrm{P}=0.197)$, Group (A) (4.74 \pm 1.60$)$ had a higher mean value of bone height percentage change than group (B) $(3.61 \pm 0.95)$ yet these differences were statistically not significant $(\mathrm{P}=0.215)$. this came in agreement with previous study, that reported insignificant higher percentage change for bone height in complete denture wearers $^{(16)}$

Another study reported that overdentures supported by anterior implant may cause accelerated 
bone loss percentage when compared to conventional dentures ${ }^{(19)}$.

Regarding Patient satisfaction to complete dentures were high this result was logic result as the flexible denture base material enhance denture retention these results met with other previous studies $^{(10,20) \text {. }}$

Regarding Frequency and percentage values for answers to the patient satisfaction questionnaire statistical analysis revealed that there was no significance difference between answers of the two groups, this came in accordance with previous study which reported that, there were no significant differences between both groups in relation to comfort, aesthetics, chewing ability, overall satisfaction, pain, functional, phonetic, social, and psychological limitations ${ }^{(21)}$. Although the stability of the mandibular implant overdenture was enhanced compared to a conventional denture, the quality of life and satisfaction levels were similar for both ${ }^{(21,22)}$.

One of contributing factor for the high level of satisfaction in group (A) was the excellent physical and functional quality of their prostheses. While lack of these qualities, considered a strong indication for the fabrication of overdentures for elderly patients ${ }^{(22,23)}$.

Reduction of the alveolar ridge in the two studied groups was expected, which perhaps a consequence of forces transmitted to the ridge that go beyond the physiological limit of tolerance for the alveolar ridge. Also wearing of the denture on the whole changes the biology of the oral environment that may be accountable for the changes in the supporting soft tissues influencing the state of ridge reduction ${ }^{(24)}$.

\section{CONCLUSION}

Within the limitation of this study it could be concluded that, patients treated with flexible conventional denture had a higher mean value of bone height percentage change than those treated with flexible single implant supported overdenture in posterior area of the mandible but the difference found to be statistically not significant. Regarding patient satisfaction for both groups there was no statically significance difference between questions asked for both groups.

\section{REFERENCES}

1. Atwood, D. A. Some clinical factors related to rate of resorption of residual ridges. J Prosthet Dent. 2001; 2: 119-25.

2. Field C, Thompson M, Swain M. Prediction of mandibular bone remodelling induced by fixed partial dentures. J Bio Mech 2010 ; 9:1771-79.

3. Kumar T A, Naeem A, Verma A K, Mariyam A, Krishna D, Kumar PK. Residual ridge resorption: The unstoppable. Int J Prosthet Den.2016; 3:169-71.

4. Abirami G. Residual ridge resorption in complete denture wearers. J Pharma Sci 2016;6: 565-69.

5. Gupta S, Singh S V, Arya D. Residual ridge resorption-a review of etiology. Polymorphism 2019;2:107-13.

6. Manish K, Vinod K, Ravi G, Deepak M. Residual ridge resorption: a review. J Tech \&Science 2015;4:124-8.

7. D’Souza D. Residual ridge resorption-revisited. J Prosth Dent 2012;2:15-24.

8. Jacobson T E., Krol, A. J. A contemporary review of the factors involved in complete dentures. Part III: Support. J prosthet Dent $1983 ; 3: 306-13$.

9. Singh J P, Dhiman R K, Bedi R PS, Girish S H. Flexible denture base material: A viable alternative to conventional acrylic denture base material. J Cont clin Dent 2011 ;4:313.27-.

10. Hssan D, Sanad M ,Kabeel S. Effect of Flexible Denture Base on Retention of Complete Denture. AD JG 2016: 2: 147-51.

11. Alsabeeha N, Payne A, De Silva R ,Thomson W. Mandibular single-implant overdentures: preliminary results of a randomised-control trial on early loading with different implant diameters and attachment systems.Clin Oral Implants Res 2011; 22:330-37.

12. Liddelow G ,Henry P. A prospective study of immediately loaded single implant-retained mandibular overdentures: preliminary one-year results. J Prosthet Dent 2007; 97:126-37 
13. Crum R J, Rooney Jr G E. Alveolar bone loss in overdentures: a 5-year study. J prosthet Dent1978;6: 610-12.

14. Wright P S, Glantz P O, Randow K, Watson RM. The effects of fixed and removable implant-stabilised prostheses on posterior mandibular residual ridge resorption. Clin Oral Impl R 2002; 2:169-74.

15. Ahmad R, Chen J, Abu-Hassan MI, Li Q, Swain MV. Investigation of mucosa-induced residual ridge resorption under implant-retained overdentures and complete dentures in the mandible. . Int J Oral Maxillofac Impl 2015; 3:657-66.

16. Kvačić I, Knezović Zlatarić D, Čelebić A. Residual ridge atrophy in complete denture wearers and relationship with densitometric values of a cervical spine: a hierarchical regression analysis. J Gerodont 2012; 2: 935-94

17. Tymstra N ,Raghoebar G M, Vissink H J A ,MEIJER A .Maxillary anterior and mandibular posterior residual ridge resorption in patients wearing a mandibular implantretained overdenture J Oral Rehab.2011; 38:509-16.

18. Abrahamsson I, Berglundh T. Effects of different implant surfaces and designs on marginal bone-level alterations: a review. JClin oral impl 2009; 20: 207-15.
19. Nakai H, Niimi a, Ueda M. Osseous proliferation of the mandible after placement of endosseous implants. Int $\mathrm{J}$ Oral Maxillofac Implants 2000;3:419-24.

20. Marchini, L. Patients' satisfaction with complete dentures: an update. Brazilian Dent Sci 2014;4: 5-16

21. Assuncao WG, Zardo GG, Delben JA, and Barao V.A. Comparing the efficacy of mandibular implant-retained overdentures and conventional dentures among elderly edentulous patients: satisfaction and quality of life. Gero Dent 2007; 24: 235-38

22. Thomason JM, Lund JP, Chehade Aetal. Patientsatisfaction with mandibular implant overdenturesand conventional dentures 6 months after delivery.Int J Prosthodont 2003; 16:467- 73 .

23. Davis DM. The shift in therapeutic paradigm: osseointegration. J Prosthet Dent 1998;79:137-42.

24. Mericske S R.Treatment outcomes with implant-supported overdentures: clinical consideration.J Prosthet Dent1998; 1:66-73. 